\title{
A Case Report on Stavudine Induced Lipodystrophy
}

\author{
Lakshmi Narasimha Gunturu*, Kalpana Pamayyagari, Girirajasekhar Dornadula
}

Department of Pharmacy Practice, Annamacharya College of Pharmacy, Rajampeta, Andhra Pradesh, INDIA.

\begin{abstract}
Drug induced adverse drug reactions are more common in long term therapy particularly in immune compromised patients. Some of the drugs causes Redistribution of body fat (Lipodystrophy) in Human Immunodeficiency Virus (HIV) infected patients and loss of body fat (Lipoatrophy). Stavudine is the one of the first line regimens drugs used for HIV infection belongs to the category of Nucleoside reverse transcriptase enzyme inhibitor (NRTIs). In the present case, we have reported the stavudine induced severe Lipodystrophy (Lipoma). A patient visited the hospital with the symptoms of lump on back of neck as, she received Stavudine fixed dose combination (SLN) as a drug for her diagnosis of HIV for past seven years. After clear examination Lipodystrophy (Lipoma) was confirmed and suspected with the cause due to stavudine fixed dose regimen. The drug was stopped and the patient was opted to surgery for permanent cure. The patient was recovered from her condition and other antiretroviral drugs were recommended for her treatment.
\end{abstract}

Key words: Antiretroviral therapy, Adverse drug reaction, Lipodystrophy, HIV, Lipoatrophy.

\section{INTRODUCTION}

Stavudine is the first line fixed dosage regimen (SLN) for Human Immunodeficiency Virus (HIV) infection from the category of Nucleoside reverse transcriptase enzyme inhibitor (NRTIs). Lactic acidosis is the most common adverse drug reaction of the drug Stavudine. ${ }^{1}$ In some studies, it has been reported that the use of Stavudine fixed dosage regimen (SLN) produce the Lipodystrophy syndrome that is called as Lipoma. ${ }^{2}$ Lipodystrophy is the changes in body fat (loss/gain) and associated metabolic disturbances seen in some people living with HIV. This can be genetic or acquired. Drug reaction is most important cause for the development of Lipodystrophy. The following drugs are reported with Lipodystrophy like Stavudine, Zidovudine and protease inhibitors except Atazanavir. ${ }^{3}$

\section{CASE REPORT}

A 28 years old female patient visited to Government General Hospital, Kadapa with complaints of pain at back side of neck region in outpatient ward. She was diagnosed with HIV disease for last eight years and received Zidovudine, Lamivudine and
Nevirapine (ZLN) as initial drug fixed dose combinations of $300 \mathrm{mg}, 150 \mathrm{mg}$ and $200 \mathrm{mg}$ respectively in a single tablet twice daily. As she found anaemic $(\mathrm{Hb}<8 \mathrm{mg} / \mathrm{dl})$ after one year with this fixed dosage regimen(ZLN) her drug therapy was changed to Stavudine, Lamivudine and Nevirapine single tablet fixed dosage regimen (SLN) twice daily. After usage of SLN fixed dosage combination for seven years she developed lump at back side of neck that is fat accumulation. During her visit after clear examination the condition was diagnosed as drug induced Lipodystrophy and the suspected drug was Stavudine fixed dosage regimen (NRTIs) by the ART Physician. Her CD4+T-cell count was 878 cells $/ \mathrm{mm}^{3}$

\section{OUTCOME AND FOLLOW-UP}

After suspecting the condition, the patient was advised to stop Stavudine fixed dosage regimen (SLN) and Prescribed with another antiretroviral regimen that is Tenofovir, Lamivudine and $300 \mathrm{mg}, 300 \mathrm{mg}$, 600mg respectively one tablet taken once a day on empty stomach. Patient was continued with the prescribed TLE regimen for five years but left Lipoma condition untreated as
DOI: 10.5530/ijopp.14.3.44

Address for correspondence: Dr. Lakshmi Narasimha Gunturu Department of Pharmacy Practice, Annamacharya College of Pharmacy, Rajampeta, Andhra Pradesh, INDIA Phone no: +91-7799230296 Email Id: gunturunarasimha007@ gmail.com

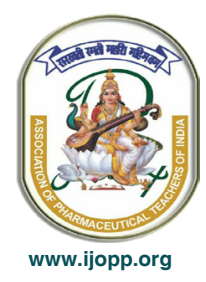


there are no drug therapies to cure Lipomas. During this period her laboratory investigations shows improvement in her $\mathrm{Hb}$ levels as $11.2 \mathrm{gm} / \mathrm{dl}$. But, the condition of Lipoma worsened that the patient is experiencing the pain diffusing towards her right shoulder. As she unable to tolerate the pain finally opted for surgery to remove lipoma. After the surgery drug regimen from TLE was changed to Tenofovir, Lamivudine and Nevirapine (TLN).

\section{DISCUSSION}

Before Stavudine treatment the patient was prescribed with Zidovudine plus Lamivudine and Nevirapine. The Lipoma was observed after initiation of the Stavudine treatment. Then after withdrawal of the Stavudine Lipoma development was stopped further on other areas of body and the patient is able to tolerate the new HAART therapy that is TLE regimen. In many studies it was reported that Stavudine was the main causative agent for Lipodystrophy that is Lipoma. ${ }^{4}$ National AIDS Control Organisation (NACO) guidelines and other evidences shows possible association between stavudine associated Lipoma as Adverse effect., ${ }^{5,6}$ The possible mechanisms by which anti-retroviral drugs induce lipodystrophy are 1) Mitochondrial toxicity 2) Insulin resistance 3) Adipose tissue gene expression derangements and 4) Proteasome dysfunction. ${ }^{7}$ Delay in discontinuing of Stavudine will still worsened the condition. The genes associated in Lipodystrophy reported in literature are UCP3, pref1. ${ }^{8}$ Post marketing surveillance of stavudine revealed increased abnormal fat re-distributions among the HIV infected patients hence this drug is no longer considered for first line regimens in recent days.

\section{CONCLUSION}

Before initiating patients on Anti-retroviral therapy patient education is instrumental regarding the potential adverse events and follow up process. Adverse drug effects are needed to be monitored and assessed using the physical examinations and laboratory values to know severity and type of Adverse effect. Managing Adverse effects in ART ward are crucial to establish a successful HIV regimen. Early withdrawal of the causative agent is essential to prevent further progression of adverse effect.

\section{Patient Consent}

Yes.

\section{CONFLICT OF INTEREST}

The authors declare no conflict of interest.

\section{ABBREVIATIONS}

HIV: Human Immunodeficiency Virus, NRTI: Nucleoside reverse transcriptase enzyme inhibitor, HAART: Highly Active anti-retroviral Therapy.

\section{REFERENCES}

1. Hilal-Dandan R, Laurence BL. Antiretroviral agents and Treatment of HIV Infection. In: Goodman and Gilman's manual of Pharmacology and Therapeutics. $2^{\text {nd }}$ Edition; 2014.

2. Khan K, Khan AH, Sulaiman SA, Soo CT, Ahsan R. Adverse Effect of Highly Active Anti-retroviral Therapy (HAART) in HIVIAIDS Patients. Indian J Pharm Pract. 2014;7(3):29-36.

3. National Techniqual Guidelines on Anti-retroviral Treatment. 2018.

4. Janneh O, Hoggard PG, Tjia JF, Jones SP, Khoo SH, Maher B, et al. Intracellular disposition and metabolic effects of zidovudine, stavudine and four protease inhibitors in cultured adipocytes. Antivir Ther. 2003;8(5):417-26.

5. Mercier S, Gueye NF, Cournil A, Fontbonne A, Copin N, Ndiaye I, et al. Lipodystrophy and Metabolic Disorders in HIV-1-Infected Adults on 4- to 9-Year Antiretroviral Therapy in Senegal: A Case-Control Study. J Acquir Immune Defic Syndr. 2009;51(2):224-30.

6. Kalyanasundaram AP, Jacob SM, Hemalatha R, Sivakumar MR. Prevalence of Lipodystrophy and Dyslipidemia among Patients with HIV Infection on Generic ART in Rural South India. J Int Assoc Physicians AIDS Care. 2012;11(5):32934.

7. Mallewa JE, Wilkins E, Vilar J, Mallewa M, Doran D, Back D, et al. HIVassociated lipodystrophy: A review of underlying mechanisms and therapeutic options. J Antimicrob Chemother. 2008;62(4):648-60.

8. Giralt M, Domingo P, Guallar JP, Concepción RDLAML, Alegre M, Domingo JC, et al. HIV-1 infection alters gene expression in adipose tissue, which contributes HIV-1/ HAART associated lipodystrophy. Antivir Ther. 2006;11(6):729-40. 